\title{
Distinct cis-Regulatory Elements from the Dlx1/Dlx2 Locus Mark Different Progenitor Cell Populations in the Ganglionic Eminences and Different Subtypes of Adult Cortical Interneurons
}

\author{
Noël Ghanem, ${ }^{1}$ Man Yu, ${ }^{1}$ Jason Long, ${ }^{2}$ Gary Hatch, ${ }^{1}$ John L. R. Rubenstein, ${ }^{2}$ and Marc Ekker ${ }^{1}$ \\ ${ }^{1}$ Centre for Advanced Research in Environmental Genomics, Department of Biology, University of Ottawa, Ottawa, Ontario, Canada K1N 6N5, and 2Nina \\ Ireland Laboratory of Developmental Neurobiology, Centre for Neurobiology and Psychiatry Genetics, Department of Psychiatry, University of California, \\ San Francisco, San Francisco, California 94143
}

\begin{abstract}
Distinct subtypes of cortical GABAergic interneurons provide inhibitory signals that are indispensable for neural network function. The $D l x$ homeobox genes have a central role in regulating their development and function. We have characterized the activity of three cis-regulatory sequences involved in forebrain expression of vertebrate Dlx genes: upstream regulatory element 2 (URE2), I12b, and I56i. The three regulatory elements display regional and temporal differences in their activities within the lateral ganglionic eminence (LGE), medial ganglionic eminence (MGE), and caudal ganglionic eminence (CGE) and label distinct populations of tangentially migrating neurons at embryonic day 12.5 (E12.5) and E13.5. We provide evidence that the dorsomedial and ventral MGE are distinct sources of tangentially migrating neurons during midgestation. In the adult cortex, URE2 and I12b/I56i are differentially expressed in parvalbumin-, calretinin-, neuropeptide Y-, and neuronal nitric oxide synthase-positive interneurons; I12b and I56i were specifically active in somatostatin-, vasoactive intestinal peptide-, and calbindin-positive interneurons. These data suggest that interneuron subtypes use distinct combinations of $D l x 1 / D l x 2$ enhancers from the time they are specified through adulthood.
\end{abstract}

Key words: ganglionic eminence; regionalization; migration; progenitors; enhancers; cerebral cortex; GABAergic neurons; homeobox; mice

\section{Introduction}

Two main classes of neocortical neurons constitute the basic functional units on which complex neuronal networks are established during development: (1) glutamatergic neurons, which are largely projection neurons; and (2) GABAergic neurons, which are local circuit neurons (Peters and Saint Marie, 1984; DeFelipe and Farinas, 1992). Inhibitory GABAergic neurons comprise 20$30 \%$ of all adult neocortical neurons (Parnavelas et al., 1977; Hendry et al., 1987; Meinecke and Peters, 1987) (for review, see Markram et al., 2004; Wonders and Anderson, 2006). They are subdivided into subtypes based on molecular, morphological, and electrophysiological features (Markram et al., 2004). Interneuron subtypes express one or more of three calcium-binding

\footnotetext{
Received 0ct. 30, 2006; revised March 7, 2007; accepted April 2, 2007.

This work was supported by Canadian Institutes of Health Research (CIHR) Grant MOP14460 (M.E.), by research grants to J.L.R.R. from Nina Ireland, and National Institutes of Health Grants R01 MH49428 and K02 MH01046. M.E. was supported by a CIHR Investigator Award during part of this work. We thank Dr. Thomas Sargent laboratory for providing the guinea pig lacZ antibody and Dr. Ruth Slack for useful comments on this manuscript. We thank Dr. Luc Poitras for his assistance in drawing the model shown in Figure 10 and Adrianna Gambarotta for creating the transgenic mice and Elaine Coderre for technical assistance with sectioning. N.G. was supported in part by a scholarship from the Lebanese University, Beyrouth.

Correspondence should be addressed to Marc Ekker, Department of Biology, University of Ottawa, 30 Marie Curie, Ottawa, Ontario, Canada K1N 6N5. E-mail: mekker@uottawa.ca.

DOI:10.1523/JNEUROSCI.4725-06.2007

Copyright $\odot 2007$ Society for Neuroscience $\quad$ 0270-6474/07/275012-11\$15.00/0
}

proteins [parvalbumin (PV), calretinin (CR), and calbindin (CB)] and four neuropeptides [somatostatin (SOM), neuropeptide Y (NPY), vasoactive intestinal peptide (VIP), and cholecystokinin (CCK)] (Markram et al., 2004).

In rodents, most interneurons in the neocortex, hippocampus, and olfactory bulb are derived from the embryonic basal ganglia (for review, see Parnavelas, 2000; Corbin et al., 2001; Marin and Rubenstein, 2001). Immature interneurons migrate along distinct routes toward their destinations, where they differentiate. Tangential migration, in which cells migrate orthogonally to the radial axis of the neural tube, is the major direction followed by ventrally derived interneurons to reach the dorsal cortex and hippocampus. Distinct subtypes of interneurons have different spatiotemporal origins (Wichterle et al., 2001; Anderson et al., 2002; Valcanis and Tan, 2003; Xu et al., 2004; Butt et al., 2005). For example, the PV-and SOM-expressing interneurons seem to derive primarily from progenitors located in the medial ganglionic eminence (MGE) between embryonic day 12.5 (E12.5) and E16.5. In contrast, interneurons expressing CR derive exclusively from progenitors found in the caudal ganglionic eminence (CGE) between E14.5 and E16.5 (Xu et al., 2004; Butt et al., 2005).

The mechanisms that specify cortical interneuron subtypes may be explained by yet unknown microenvironments within a 
given progenitor domain created by the combinatorial expression of various molecules, including transcription factors. The environment in which the interneurons migrate and settle may also contribute to their fate determination.

The $D l x$ family comprises six genes organized into three bigene clusters on separate chromosomes. Four of them, $D l \times 1, D l \times 2$, $D l \times 5$, and Dlx6 are sequentially expressed in the subcortical telencephalon starting around embryonic day 9.5 (E9.5) (Liu et al., 1997; Eisenstat et al., 1999). They display overlapping expression patterns in the basal ganglia (subpallium) but with subtle differences [for review, see (Panganiban and Rubenstein, 2002)]. Mutants lacking $D l \times 1 / D l \times 2$ function display a block in the differentiation of progenitors in the basal ganglia and lack of migrations to the cerebral cortex, olfactory bulb, and hippocampus (Anderson et al., 1997a,b).

We previously identified cis-regulatory elements (CREs) located in the intergenic regions of the $D l \times 1 / D l \times 2$ and $D l \times 5 / D l \times 6$ loci of vertebrates. These CREs (I56i, I56ii, and I12b) are able to target reporter transgene expression to the subpallial telencephalon and to the diencephalon of transgenic animals (Zerucha et al., 2000; Ghanem et al., 2003).

Here, we compare the spectrum of activity of I12b, I56i, and that of a novel CRE, upstream regulatory element 2 (URE2), located in the $5^{\prime}$ flanking region of $D l x 1$. The three CREs display differential activities in the dorsal, medial, and ventral parts of the lateral ganglionic eminence (dLGE, mLGE, and vLGE), MGE (dMGE, mMGE, and vMGE), and CGE (dCGE, mCGE, and vCGE) and mark distinct populations of tangentially migrating neurons. Furthermore, we show that URE2 and I12b/I56i are differentially active in several subtypes of adult cortical interneurons.

\section{Materials and Methods}

Transgenic mice. To generate transgenic mice, the enhancer sequences of URE2, I12b, and I56i were subcloned into the p1229/p1230 vectors (Yee and Rigby, 1993) that contain a human $\beta$-globin minimal promoter and the lac $Z$ reporter gene. The URE2 sequences from human, mouse, and Takifugu rubripes were obtained from public databases: human, GenBank accession number NT_005403.16, position 23146508-23147458; mouse, GenBank accession number NT_039207.6, position 123964251239757; and Takifugu rubripes, GenBank accession number CAAB01001300.1, position 46685-47635. Subclonings were done using either a PCR-based approach or using convenient restriction sites. The p1230-based I12b-alkaline phosphatase construct was generated by replacing the lac $Z$ reporter gene with the human placental alkaline phosphatase gene (PLAP) in the p1230-based I12b-lac Z plasmid using Bam HI sites. The human PLAP sequence was amplified by PCR from the pGT0PFS plasmid. Transgenic animals were produced and analyzed as described previously (Zerucha et al., 2000).

Morphological analysis of transgenic mice. Embryos from the mating of a transgenic $C D 1$ male with normal $C D 1$ females were harvested at various embryonic stages. Pregnant females were killed by cervical dislocation. E11.5 and E12.5 mouse embryos were fixed in $4 \%$ paraformaldehyde (PFA) for $1-2 \mathrm{~h}$ at room temperature $(\mathrm{RT})$ and then washed in $(1 \times)$ $\mathrm{PBS}$ for $30 \mathrm{~min}$ and stained for $\beta$-galactosidase activity overnight $(\mathrm{O} / \mathrm{N})$ at $28^{\circ} \mathrm{C}$ in a solution of $1 \mathrm{mg} / \mathrm{ml} \mathrm{X}$-gal, $5 \mathrm{mM} \mathrm{K}_{3} \mathrm{Fe}(\mathrm{CN})_{6}, 5 \mathrm{~mm}$ $\mathrm{K}_{4} \mathrm{Fe}(\mathrm{CN})_{6}, 2 \mathrm{mM} \mathrm{MgCl}_{2}$, and $0.02 \% \mathrm{NP}-40$ in PBS. Mouse brains were dissected out after staining and soaked in $20 \%$ sucrose solution at $4^{\circ} \mathrm{C}$ $\mathrm{O} / \mathrm{N}$. The following day, brains were cryoprotected and frozen using cold isopentane (kept at $-80^{\circ} \mathrm{C}$ ). Thirty to $50 \mu \mathrm{m}$ sections were then cut using a cryostat [Leica (Nussloch, Germany) CM3050 S].

Sectioning and tissue preparation of adult brains. Postnatal day 35 (P35) adult mice were screened by PCR with specific primers for lac $Z$ and/or PLAP using genomic DNA extracted from ear tissue. Positive mice were anesthetized with isoflurane and were subjected to cardiac perfusion in $1 \times$ PBS followed by $4 \%$ cold PFA. Brains were dissected out afterward and postfixed in $4 \%$ PFA for $4 \mathrm{~h}$ at RT. Sections of $30-40 \mu \mathrm{m}$ thickness were cut into cold $0.1 \mathrm{M}$ phosphate buffer $(\mathrm{PB})$ using a vibratome (Vibratome series 1000; Technical Products International, Winnipeg, Manitoba, Canada).

Double immunohistochemistry. Sections of E12.5 and E13.5 mouse brain were generated as described above. Frozen sections were dried for $1 \mathrm{~h}$ and then washed three times for $5 \mathrm{~min}$ each in $0.1 \mathrm{M} \mathrm{PB}, \mathrm{pH} 7.4$, to eliminate residues from tissue protection medium. Sections were incubated in blocking solution: $1 \%$ bovine serum albumin, $5 \%$ goat serum, and $0.3 \%$ Triton-X in $0.1 \mathrm{~m} \mathrm{~PB}$ for at least $1 \mathrm{~h}$ at RT. This was followed by incubation with the primary antibody at $4^{\circ} \mathrm{C} \mathrm{O} / \mathrm{N}$. Three $10 \mathrm{~min}$ washes in $0.1 \mathrm{M}$ PB were performed the next day. This was followed by incubation with the secondary antibody for $2 \mathrm{~h}$ at RT away from light. Sections were washed three times for $10 \mathrm{~min}$ each, processed for a second round of immunohistochemical labeling and, finally, mounted in Immuno Fluore mounting media (Fisher, Pittsburgh, PA).

Immunohistochemistry on floating sections of adult mouse tissue was performed as described previously (Cobos et al., 2005). We used the following antibodies: guinea pig anti- $\beta$-galactosidase (1:1000; generous gift from Thomas Sargent laboratory), rabbit anti-PLAP (1:100; Serotec, Raleigh, NC), rabbit anti-PV [1:1000; Swant (Bellinzona, Switzerland) Swiss Antibodies], rat anti-SOM (1:100; Millipore, Billerica, MA), rabbit anti-neuronal nitric oxide synthase (nNOS; 1:150; Zymed/Invitrogen, San Francisco, CA), rabbit anti-CR (1:4000; Swant Swiss Antibodies), rabbit anti-NPY (1:4000; ImmunoStar, Hudson, WI), rabbit anti-TH (1:350; Millipore), rabbit anti-GABA (1:4000; Sigma, St. Louis, MO), rabbit anti-VIP (1:200; ImmunoStar), and rabbit pan-Dll antibody (anti$D l x$; a gift from G. Boekhoff-Falk, University of Wisconsin, Madison, WI). Secondary antibodies were purchased from Invitrogen (Eugene, OR): goat anti-rabbit Alexa Fluor 488, goat anti-guinea pig Alexa Fluor 594, and goat anti-rat Alexa Fluor 488.

In coimmunolocalization studies, when both signals could be detected in the same cell, regardless of their respective intensities, the cell was counted as being positive for both antigens.

Cell counts and brain sampling. Cell counts were performed on digitized images obtained from randomly selected areas of layers I-VI of the somatosensory and motor cortices using 8-10 coronal sections from different positions along the rostrocaudal axis. Cells expressing $\beta$-galactosidase and/or interneuron markers were counted. Quantification was determined from two independent transgenic lines using four brains per line $(n=4)$ and averaged. Data are presented as mean \pm SD.

Organotypic culture. Organotypic slice cultures of embryonic mouse forebrain were performed as described previously (Anderson et al., 1997b). For the transplantation experiment and because of the small size of the tissue, we divided the MGE into two portions instead of three: $\mathrm{dMGE} / \mathrm{mMGE}$ and vMGE.

\section{Results}

\section{Regulation of $D l x$ gene expression in the forebrain by tissue-specific enhancers}

The previously identified CREs, I56i and I12b, located in the intergenic regions of $D l \times 5 / D x 6$ (Zerucha et al., 2000) and $D l \times 1 /$ Dlx2 (Ghanem et al., 2003), respectively, show comparable regulatory activities in the subpallial telencephalon and diencephalon when examined in whole-mount transgenic mouse embryos (Ghanem et al., 2003). In a search for additional regulatory elements controlling $D l x 1$ and $D l x 2$ gene expression in the forebrain, we examined, by "phylogenetic footprinting," the 5 ' flanking regions of each gene for conserved noncoding DNA sequences among mouse, human, Takifugu rubripes, and zebrafish. We identified two conserved sequences in the 5 ' flanking region of Dlx1 that we named URE1 and URE2. The two sequences were found in all of the vertebrate species listed above as well as others. In the mouse, they are located $\sim 17 \mathrm{~kb}$ (URE1) and $\sim 12 \mathrm{~kb}$ (URE2) upstream of the Dlx1 ATG start site (Fig. 1A; supplemental sequence information, available at www.jneurosci.org as supplemental material). 
A
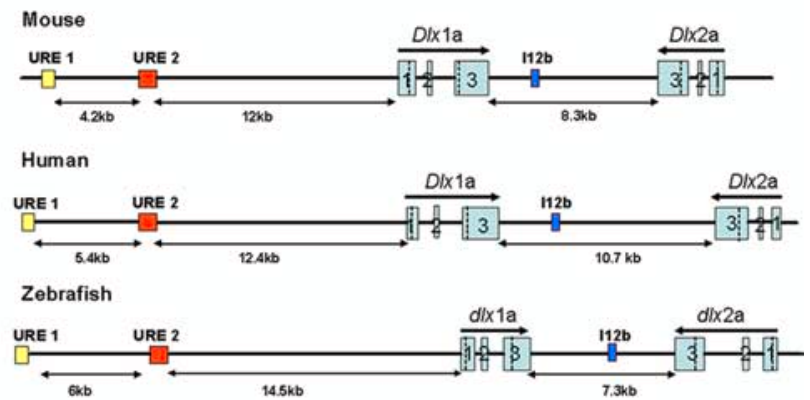

Takifugu rubripes

B

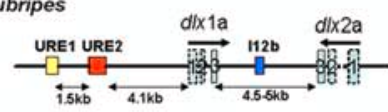

$400 \mathrm{bp}$

둘 $900 \mathrm{bp}$

$\square 600 \mathrm{bp}$

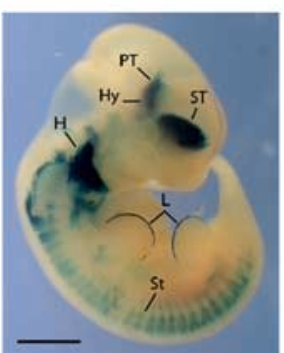

Figure 1. Conserved cis-acting regulatory elements in the $D / x 1 / D / \times 2$ locus. $A$, Schematic representation of the $D / x 1 / D / x 2$ locus of four vertebrate species. Each $D / x$ gene comprises three exons, which are indicated in light blue boxes. Colored squares are conserved noncoding DNA sequences: 112b (blue), URE1 (yellow), and URE2 (red). B, Enhancer activity of the mouse URE2 sequence in an E11.5 mouse embryo. URE2 targets lacZ reporter gene expression to two domains in the forebrain, the subpallial telencephalon, and diencephalon, as well as other tissues. H, Hyoid arch (second arch); Hy, hypothalamus; L, limbs; PT, prethalamus (ventral thalamus); ST, subpallial telencephalon; St, somites. Scale bar, $1 \mathrm{~mm}$.

We looked for a potential regulatory role played by URE1 and URE2 by generating transgenic mice using a construct comprised of a lac $Z$ reporter gene under the control of the human $\beta$-globin minimal promoter. Analysis of the $\beta$-galactosidase activity in the URE2-lacZ transgenic lines at E11.5 showed that URE2 is active in the forebrain of these mice as well as the hyoid arch, the somites, and the apical ectodermal ridge of the limbs (Fig. $1 B$ ). Expression of lac $Z$ in the forebrain is restricted to the subpallial telencephalon, the prethalamus, and the hypothalamus and was consistent among independently generated transgenic lines. In wholemount preparations, URE2-lacZ reporter activity in the forebrain is reminiscent of the activities of I12b-lacZ and I56i-lacZ (Ghanem et al., 2003). The other CRE, URE1, showed no activity in the forebrain but is active in other regions of the embryo, notably in the retina, and will not be discussed further here. We also examined the $5^{\prime}$ flanking region of $D l \times 2$ but did not find sequences that were conserved among the five species.

\section{Dlx enhancers identify divisions in the LGE, MGE, and CGE}

We compared the expression of lac $Z$ driven by URE2, I12b, and I56i in coronal sections of E11.5 and E12.5 telencephalon. Results were confirmed using at least two independent transgenic lines. The I12b-lacZ and I56i-lacZ transgenic embryos display nearly indistinguishable reporter expression at E11.5 and E12.5 in the subventricular zone (SZV) and mantle zone (MZ) of the subpallium, the LGE, the MGE, anterior entopeduncular area (AEP), preoptic area (POA), and in the CGE (Fig. 2). URE2-lacZ transgenic lines display distinct reporter gene expression in two main regions.

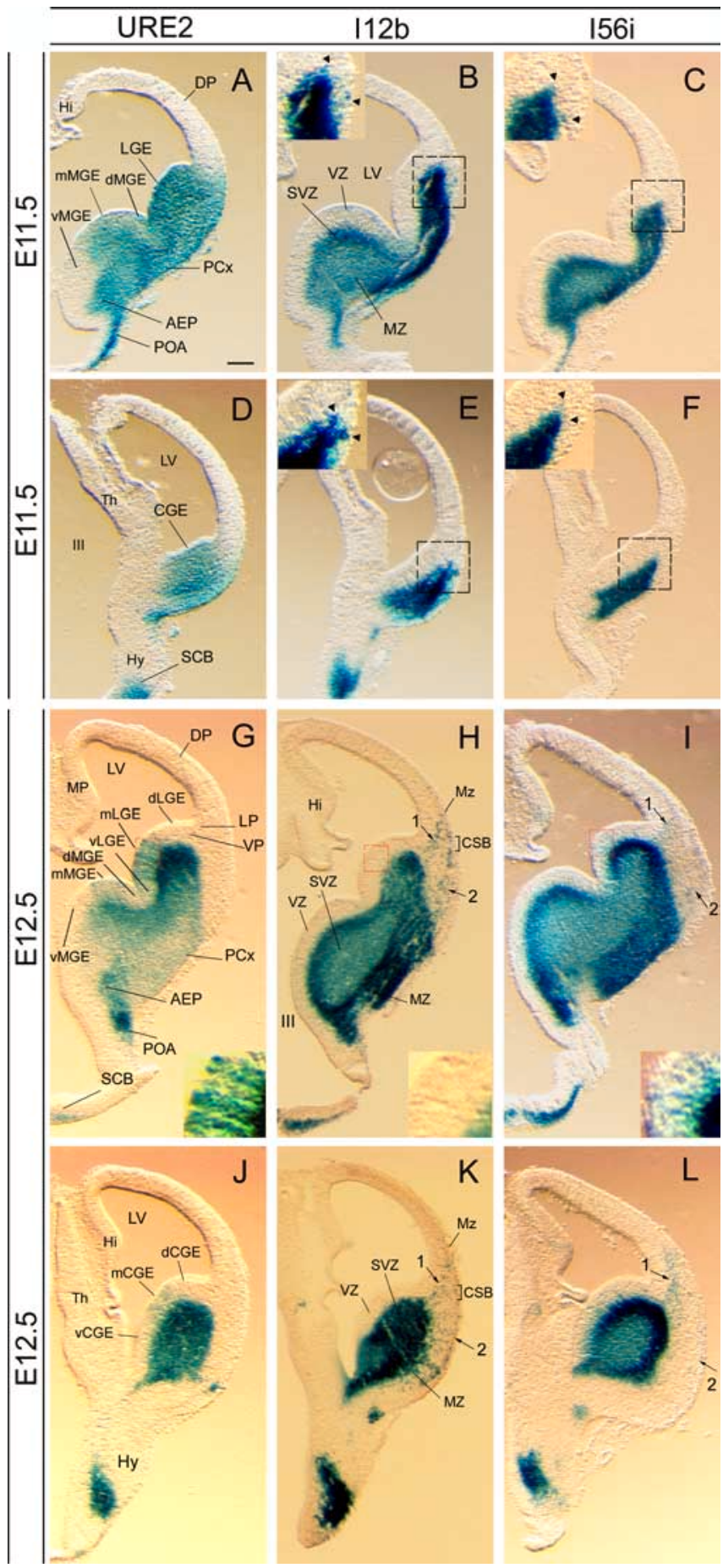

Figure 2. Comparative enhancer activities of URE2, I12b, and I56i in the subpallial telencephalon of transgenic mice. Coronal hemisections showing lacZ expression under the control of each enhancer at E11.5 ( $\boldsymbol{A}-\boldsymbol{F})$ and E12.5 (G- $\boldsymbol{L})$ in medial and caudal levels. $\boldsymbol{A}, \mathbf{D}, \mathbf{G}, \mathbf{J}$, URE2-lacZ; $B, E, H, K, I 12 b$-lacZ; C, F, I, L, I56i-lacZ. B, C, E, F, Insets, Higher-magnification pictures of regions shown in black dashed boxes; arrowheads in the insets mark the beginning of tangential migrations at the level of the dLGE at E11.5. G, $\boldsymbol{H}, \boldsymbol{I}$, Insets, Higher-magnification pictures of the red dashed boxes. $\boldsymbol{H}, \boldsymbol{I}, \boldsymbol{K}, \boldsymbol{L}$, Arrows 1 and 2 show the two streams of migratory cells emerging from the LGE at the level of the corticostriatal boundary (CSB), which coalesce into one stream within the cortex at E12.5: a superficial stream (stream 1) and a deep stream (stream 2). Tangential migration of URE2-lacZ-positive cells was not observed at these stages. III, Third ventricle; $\mathrm{CP}$, cortical plate; Hi, hippocampus; Hy, hypothalamus; LV, lateral ventricle; $\mathrm{PC}$, piriform cortex; $\mathrm{SCB}$, suprachiasmatic band; $T$, thalamus; $\mathrm{VP}$, ventral pallium; $\mathrm{VZ}$, ventricular zone. Scale bar: (in $\boldsymbol{A}) \boldsymbol{A}-\boldsymbol{L}, 250 \mu \mathrm{m} ; \boldsymbol{B}, \boldsymbol{C}, \boldsymbol{E}, \boldsymbol{F}$, insets, $125 \mu \mathrm{m} ; \boldsymbol{G}, \boldsymbol{H}, \boldsymbol{I}$, insets, $75 \mu \mathrm{m}$. 


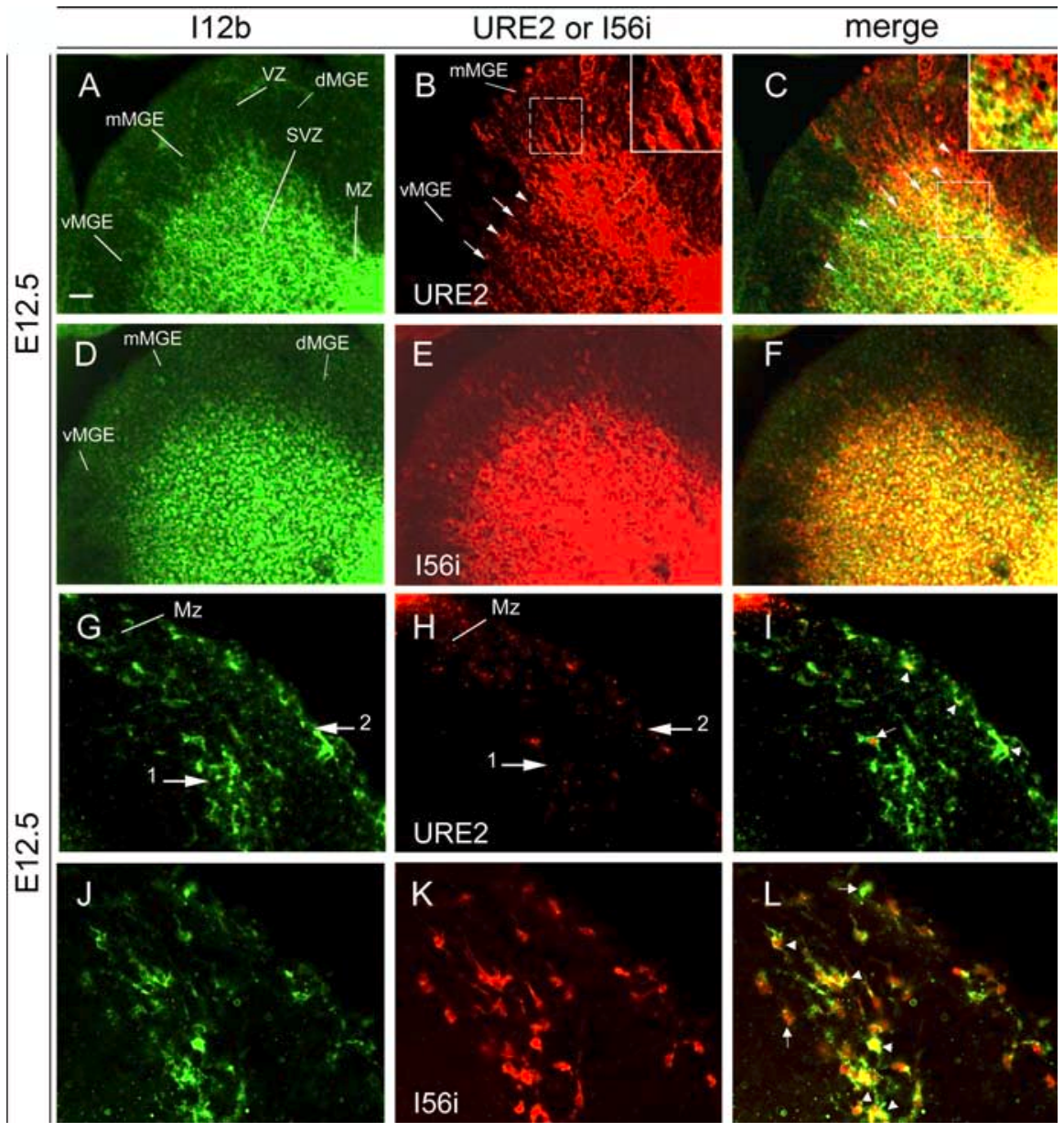

Figure 3. Activities of three DIX CREs in the MGE and in the cortex near the CSB at E12.5. $\boldsymbol{A}-\boldsymbol{F}$, Double immunohistochemistry showing the expression of $/ 12 b$ - $A P$ in green $(\boldsymbol{A}, \boldsymbol{D})$, URE2-lacZ $(\boldsymbol{B})$, or I56i-lacZ in red $(\boldsymbol{E})$. $\boldsymbol{C}, \boldsymbol{F}$, Merged pictures of $\boldsymbol{A}, \boldsymbol{B}$ and $\boldsymbol{D}, \boldsymbol{E}$, respectively. Compared with the dMGE, only few radial columns of cells in $\boldsymbol{B}$ express URE2-lacZ in the SVZ of vMGE (arrowheads), whereas others do not (arrows). In $\boldsymbol{C}$, arrows and arrowheads show radial columns of double-labeled cells (yellow) and singlelabeled ones (red or green), respectively. Insets in $\boldsymbol{B}$ and $\boldsymbol{C}$ are high-magnification pictures of the areas shown in white dashed boxes. $\mathbf{G}-\boldsymbol{L}$, Labeling of tangentially migrating cells in the cortex near the CSB of /12b-AP mice (G, J; green), URE2-IacZ mice (H; red), and $/ 56$ i-lacZ mice ( $\boldsymbol{K}$; red) atE12.5. I, $\boldsymbol{L}$, Merged pictures of $\mathbf{G}, \boldsymbol{H}$ and $\boldsymbol{J}, \boldsymbol{K}$, respectively. As described in Figure 2, migratory cells in $\boldsymbol{H}, \boldsymbol{I}, \boldsymbol{K}$, and $\boldsymbol{L}$ follow superficial (stream 1) and deep (stream 2) streams of migrations at E12.5 that will merge into one along the Mz of the CSB. $\boldsymbol{H}$, There is little URE2-IacZ expression in tangentially migrating cells at this age. $\boldsymbol{I}, \boldsymbol{L}$, Single-labeled and doublelabeled cells are indicated with arrows and arrowheads, respectively. Scale bar: (in $\boldsymbol{A}) \boldsymbol{A}-\boldsymbol{L}, 25 \mu \mathrm{m} ; \boldsymbol{B}, \boldsymbol{C}$, insets, $15 \mu \mathrm{m} ; \boldsymbol{G}-\boldsymbol{L}, 12.5$ $\mu \mathrm{m}$. Symbols are the same as in Figure 2.

(1) URE2-lacZ was the only CRE directing expression to the ventricular zone (VZ), in which it is expressed in the LGE, mMGE, and CGE at E11.5 (Fig. 2A,D). URE2-lacZ expression in the VZ weakens by E12.5 in the dLGE and vLGE, the dMGE and vMGE, and the dCGE and vCGE (Fig. 2G,J); thus, its expression remains strong in the mLGE, mMGE, and mCGE (Fig. 2G,J). Cells expressing URE2-lacZ in the $\mathrm{VZ}$ are arranged in radial chains, suggesting that they may be clonally related (Figs. 2G,J, $3 B$; supplemental Fig. $\mathrm{S} 1 B$, available at www.jneurosci.org as supplemental material). This activity is weak before E11.5 (data not shown) and is maintained at least until E15.5 although with weaker intensity (data not shown). Thus, contrarily to I12b and I56i, URE2 is active in subpopulation(s) of VZ progenitor cells between E11.5 and E15.5. Note that, at these ages, cells in the VZ including those expressing URE2-lacZ are undifferentiated progenitors and do not express GABA, which is an early differentiation marker that labels committed progenitors mainly found in the subventricular zone (SVZ) and MZ (Ferguson et al., 2005).
(2) URE2-lacZ is differentially expressed in subpallial SVZ domains. Only a small number of cells express the URE2lac $Z$ transgene in the vMGE and AEP (Fig. 2A,G). This markedly contrasts with the stronger expression of $I 12 b$-lac $Z$ and of $I 56 i$-lac $Z$ in those regions (Fig. $2 B, C, H, I, K, L)$. Thus, the distinct spatiotemporal activities of URE2, compared with I12b and I56i, provide genetic evidence for three subdivisions of the LGE, MGE, and CGE.

\section{URE2 and I12b label distinct populations of tangentially migrating interneurons}

To address whether the three CREs (URE2, I12b, and I56I) are active in distinct and/or overlapping subsets of cells of the developing telencephalon, we generated a transgenic mouse line in which the human alkaline phosphatase gene, $A P$, is driven by the $112 \mathrm{~b}$ sequence (I12b-AP transgene). We crossed $I 12 b$-AP mice with I56i-lacZ and URE2-lacZ lines separately and screened the $\mathrm{F} 1$ generations for lac $Z+$ and $A P+$ double-hemizygote embryos. Then, we compared the expression patterns of the two reporter genes, at E12.5 and E13.5, by double immunohistochemistry on brain sections using antibodies against $\beta$-galactosidase and AP. First, we compared the activities of URE2 and I12b at E12.5. In the mMGE, URE2-lacZ expression is observed in a subset of cells in the $\mathrm{VZ}$ that are arranged in radial chains (Fig. $3 B$, inset), whereas $I 12 b-A P$ expression is not detected except in few columns of cells at the VZ/SVZ boundary (Fig. $3 A$ ).

Both transgenes are expressed in larger subsets of cells in the SVZ, many of which are double labeled, but some are single labeled (Fig. 3C, inset).

In the dMGE, vMGE, and AEP, URE2lac $Z$ expression is weaker than in the mMGE; it was weak or absent in the VZ and restricted to some radial columns of cells in the SVZ (Figs. $2 G, 3 B$, arrows; data not shown). In contrast, $I 12 b$-lacZ (or $I 12 b$-AP) expression, although not detected in the VZ, appears homogenous in the SVZ throughout the MGE and AEP (Figs. $2 \mathrm{H}, 3 \mathrm{~A}$, and data not shown). Similar differences in the profiles of expression of the two transgenes are detected in the LGE at this age (Fig. 2G,H and data not shown).

The URE2- and I12b-containing transgenes also show differences in CGE expression (Fig. $2 J-L$ and supplemental Fig. $\mathrm{S} 1 A-C$, available at www.jneurosci.org as supplemental material). URE2-lacZ expression is present in the VZ of the mCGE but not in the dCGE or vCGE (Fig. $2 J$, supplemental Fig. $S 1 B$, available at www.jneurosci.org as supplemental material). Furthermore, URE2-lacZ expression is weaker in the SVZ and MZ of the vCGE compared with the dCGE and mCGE (Figs. $2 J$, supplemental Fig. S1 $B$, available at www.jneurosci.org as supplemental material). 
The majority of URE-lacZ- and I12blacZ-positive cells in the ganglionic eminences express $D l x$ genes between E12.5 and E13.5, as shown by immunolocalization with a pan-Dll antibody (supplemental Fig. S6, available at www.jneurosci.org as supplemental material, and data not shown).

The distinct activities of the Dlx CREs within the MGE and CGE prompted us to investigate whether the enhancers are differentially active in interneurons that tangentially migrate to the cortex. Most cortical GABAergic interneurons in mouse are derived from the MGE and CGE (Marin and Rubenstein, 2001, 2003; Nery et al., 2002; Xu et al., 2004; Butt et al., 2005) and express Dlx genes (Anderson et al., 1997a; Stuhmer et al., 2002b; Cobos et al., 2005, 2006).

At early stages of the tangential migrations, cells express $I 12 b$-lacZ much more than they express URE2-lacZ. Of the two transgenes, I12b-lacZ is the only one expressed in migrating cells at E11.5 (Fig. $2 B, E$, arrowheads in insets). By E12.5, there are two streams of tangentially migrating cells entering the pallium at its boundary with the dLGE and dCGE; these correspond to two migratory routes known to be $D l x+$ (Lavdas et al., 1999; Anderson et al., 2001; Marin and Rubenstein, 2001; Wichterle et al., 2001). One is a deep stream that traverses the SVZ of the ventral pallium (VP) and lateral pallium (LP) and enters the SVZ/intermediate zone (IZ) of the dorsal pallium (DP) (Fig. 2 , stream 1); the second is a superficial stream that traverses the mantle of the VP and $\mathrm{LP}$ and continues in the marginal zone $(\mathrm{Mz})$ of the DP (stream 2) (Figs. $2 H-L$, $3 G-I$, arrows 1 and 2). There are approximately three to four times more $I 12 b-A P$ expressing than URE2-lacZ-expressing cells that tangentially migrate from the MGE and CGE at this age (Figs. 3G-H, $4 A$, and data not shown). However, the $I 12 b-A P$ and the I56i-lac $Z$ transgenes were expressed in the same cells in $\sim 80 \%$ of the cases (Fig. 4C).

By E13.5, a larger number of tangentially migrating neurons express URE2lac $Z$ in the cortical IZ and $\mathrm{Mz}$ (Figs. $5 B, H$, supplemental Figs. S2 $B$, S2 $H$, available at www.jneurosci.org as supplemental material). Yet, there are still $\sim 2$ - to 2.5 -fold fewer URE2-lacZ-expressing cells than I12b-AP- (Fig. $4 B$ ) or I56i-lacZ- (Fig. 4D) expressing cells. At E14.5, the number of URE2-lacZ migrating cells reaches a peak and then starts to decrease at E15.5 (data not shown). The URE2-lacZ and I12b-lacZ transgenes are expressed in a third migratory pathway that runs through the cortical SVZ, deep to the Mz and IZ between E14.5 and E16.5 (data not shown). $\beta$-Galactosidase-positive neurons continue to be detected in the
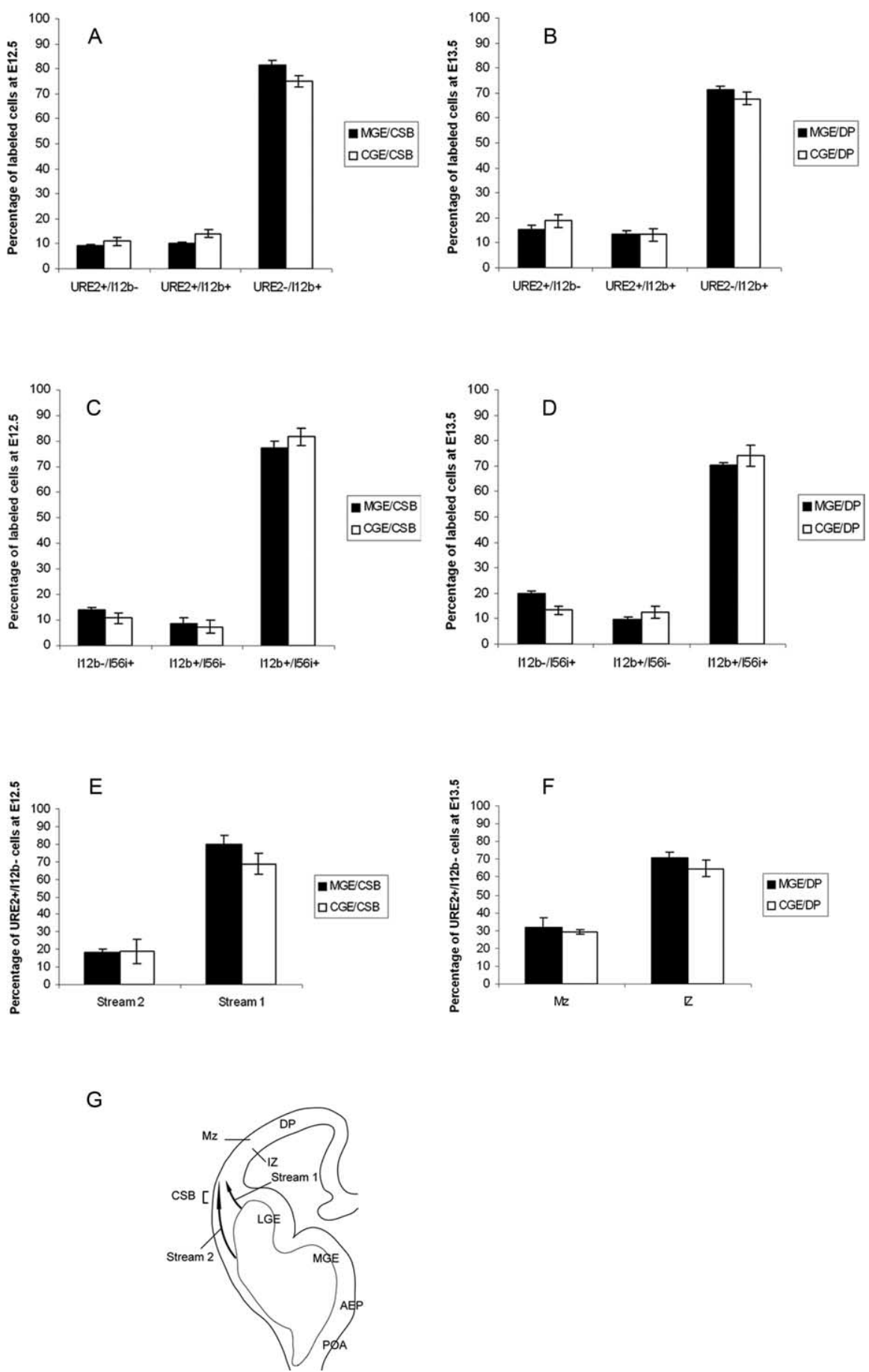

Figure 4. Differential activities of the URE2, I12b, and I56i CREs in migrating cells. $\boldsymbol{A}-\boldsymbol{F}$, Reporter transgene expression was determined at the level of the CSB at E12.5 $(\boldsymbol{A}, \boldsymbol{C}, \boldsymbol{E})$ or at the level of the DP at E13.5 $(\boldsymbol{B}, \boldsymbol{D}, \boldsymbol{F})$. The number of positive cells was determined from two to three sections per mouse of the CSB or DP at the level of the MGE or CGE (total = average from 3 mice). When both immunohistochemical signals were detected for both antigens in the same cell, regardless of signal intensity, the cell was counted as being positive for both antigens. Values are presented as mean \pm SD. G, Schematic representation of an E13 coronal hemisection of the mouse telencephalon showing the CSB, the DP, and the two streams (stream 1 and 2) of tangentially migrating cells toward the dorsal cortex. Symbols are the same as in Figure 2.

cortex at P0, P25, and P35 (see Figs. 8, 9, supplemental Fig. S5, available at www.jneurosci.org as supplemental material, and data not shown).

We compared URE2 and I12b activities in tangentially migrating cells using double labeling. Approximately one-half of the tangentially migrating cells expressing URE2-lacZ also express 


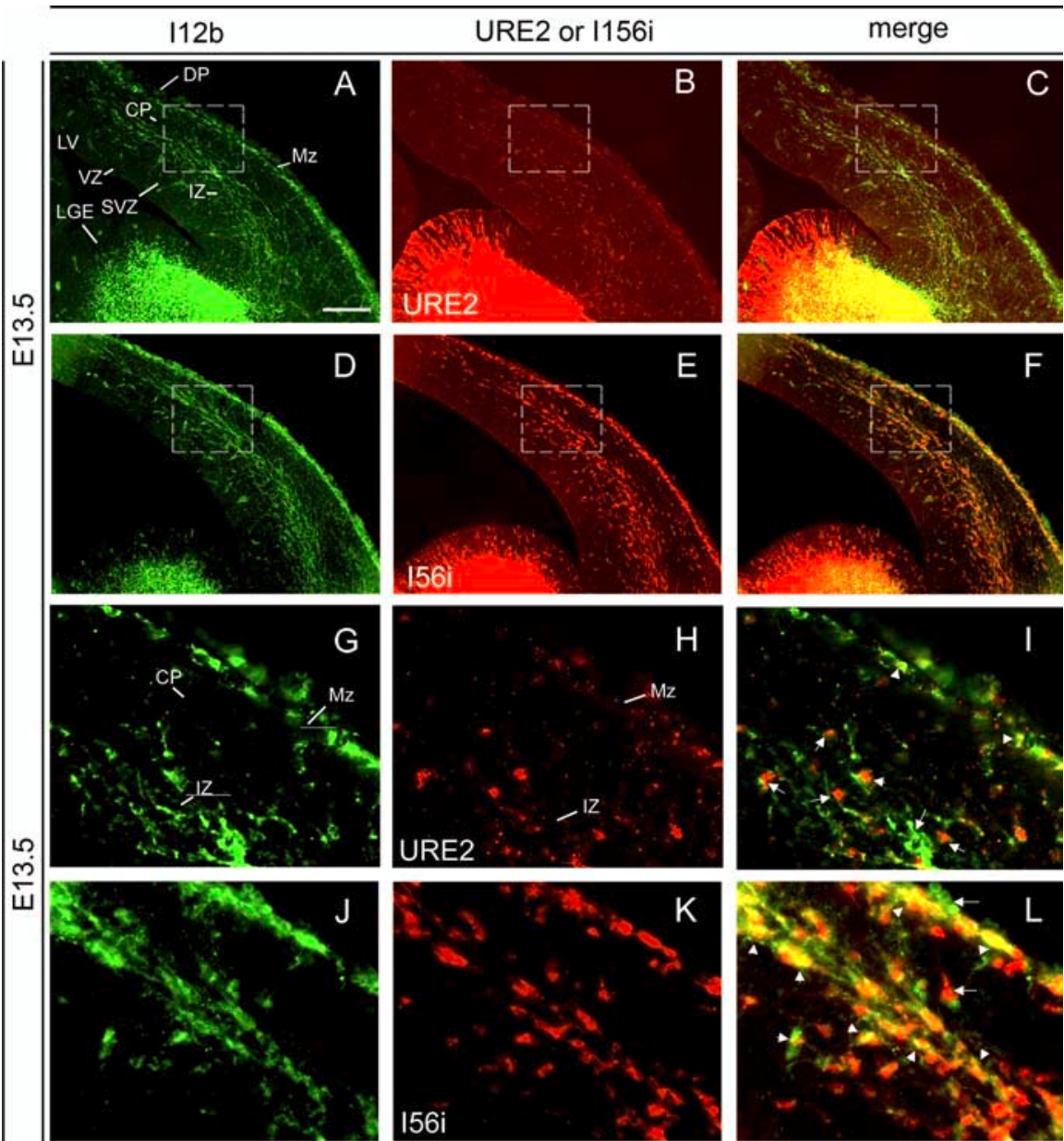

Figure 5. Activities of three $D / x$ CREs in tangentially migrating cells derived from the MGE at E13.5. $A-F$, Double immunohistochemistry showing the expression of $112 b$ - $A P$ in green $(\boldsymbol{A}, \boldsymbol{D})$ or URE2-lacZ $(\boldsymbol{B})$ or I56i-lacZ in red $(\boldsymbol{E})$, in the DP. $\boldsymbol{C}, \boldsymbol{F}$, Merged pictures of $\boldsymbol{A}, \boldsymbol{B}$ and $\boldsymbol{D}, \boldsymbol{E}$, respectively. Tangentially migrating cells follow the $\mathrm{Mz}$ and $\mathrm{IZ}$ of the DP at E13.5. $\mathbf{G}-\boldsymbol{L}$, Highermagnification pictures of the boxes shown in $\boldsymbol{A}-\boldsymbol{F}$, respectively. $\boldsymbol{I}, \boldsymbol{L}$, Merged pictures of $\boldsymbol{G}, \boldsymbol{H}$ and $\boldsymbol{J}, \boldsymbol{K}$, respectively. There are more migrating cells expressing URE2-lacZ mice at this age $(\boldsymbol{B}, \boldsymbol{H})$ compared with E12.5 (Fig. $3 H$ ). Single-labeled and double-labeled cells in $I$ and $L$ are indicated with arrows and arrowheads, respectively. Most migrating cells in /12b-AP/I56i-lacZ mice are double labeled, whereas a large number of cells in I12b-AP/URE2-lacZ mice are single labeled. Scale bar: (in $\boldsymbol{A}) \boldsymbol{A}-\boldsymbol{F}, 25 \mu \mathrm{m} ; \mathbf{G}-\boldsymbol{L}, 12.5$ $\mu \mathrm{m}$. Symbols are the same as in Figure 2.

the $I 12 b$ - $A P$ transgene at E12.5 or E13.5 (Figs. 3, $4 A, B$, supplemental Fig. S1, available at www.jneurosci.org as supplemental material). URE2-/I12b + cells are equally distributed in both stream 1 and stream 2 at E12.5 (Fig. 3I, supplemental Fig. S1 I, available at www.jneurosci.org as supplemental material) and in the IZ and Mz at E13.5 (Fig. 5I, supplemental Fig. S2 I, available at www.jneurosci.org as supplemental material). In contrast, URE2 +/I12b - migrating cells are largely found in stream 1 at E12.5 (Figs. 3I, arrows, $4 E$, and supplemental Fig. S1 $I$, available at www.jneurosci.org as supplemental material). and IZ at E13.5 (Figs. 4F, 5I, arrows and S2I). In summary, differential activity of CREs from the $D l \times 1 / D l \times 2$ locus in tangentially migrating cells suggest the existence of several populations in both the Mz and IZ.

\section{Highly similar activities of I12b and I56i}

We then compared the activities of I12b and I56i at E12.5. The majority of cells in the SVZ and MZ are double labeled in the MGE and AEP (Fig. 3D-F and data not shown) and in the CGE (supplemental Fig. $S 1 D-F$, available at www.jneurosci.org as supplemental material) confirming X-gal staining (Fig. 2) that suggests activity of the two enhancers in overlapping population(s).

We next compared the expression of I12b and I56i in tangentially migrating cells at E12.5 and E13.5 as we did for URE2/I12b comparisons. The I12b-AP and $I 56$-lacZ transgenes are coexpressed in tangentially migrating cells (Figs. $3 J-L$, $4 C, D, \quad 5 D-F, J-L$, supplemental Figs. S1 $J-L, \mathrm{~S} 2 D-F$, and $\mathrm{S} 2 J-L$, available at www.jneurosci.org as supplemental material). We also detect two populations of single-labeled migrating cells at the levels of the MGE and the CGE. The I56i+/ $\mathrm{I} 12 \mathrm{~b}-$ and the I56I-/I12b + populations accounted for $<20 \%$ and $12.5 \%$ of migrating cells, respectively (Fig. 4C,D). All three cell populations $(\mathrm{I} 12 \mathrm{~b}+/ \mathrm{I} 56 \mathrm{i}+, \mathrm{I} 12 \mathrm{~b}+/$ $\mathrm{I} 56 \mathrm{I}-$, and $\mathrm{I} 12 \mathrm{~b}-/ \mathrm{I} 56 \mathrm{i}+)$ are equally distributed between migration stream 1 and 2 at E12.5 and between the Mz and IZ at E13.5 [Figs. 3L, 5L, supplemental Figs. S1 $L$, S2L (arrows), available at www. jneurosci.org as supplemental material]. These results suggest that the I12b and I56i CRE are mainly active in the same cells and could be responding to similar regulatory factors.

\section{The dMGE/mMGE and the vMGE} produce cells that migrate to the cortex Because the I12b and URE2 CREs are differentially active in the MGE and AEP and may label distinct subpopulations of tangentially migrating neurons derived from these regions, we sought to investigate whether this could be linked to intrinsic properties of the progenitor cells found in these regions in terms of regional specification and migration potential. For this purpose, we performed in vitro DiI labeling experiments on brain slice culture taken from wild-type litters at E12.5 and E13.5. First, we compared the migration potential of neurons derived from progenitors residing in the MGE versus those derived from progenitors found in the AEP and POA, separately. We find no evidence of tangential migrations that reached the cortex from either the AEP or POA (supplemental Figs. $\mathrm{S} 3 B, C, F-H, \mathrm{~S} 4 B, D, J-L, N, P$, available at www.jneurosci.org as supplemental material), but we observe robust tangential migration of neurons from the MGE that enter the cortex (Figs. $\mathrm{S} 3 B, D$, $\mathrm{S} 4 B, C, E-H$, available at www.jneurosci.org as supplemental material) $(n=15)$ consistent with previous slice studies (Anderson et al., 1997b, 2001).

Next, we compared the migration potential of neurons derived from progenitors found in the $\mathrm{dMGE} / \mathrm{mMGE}$ versus vMGE at E12.5 and E13.5. We observe robust tangential migrations to the cortex from both regions (Fig. 6A-D, supplemental Fig. $\mathrm{S} 4 B, C, E-H, N, O$, available at www.jneurosci.org as supplemental material; data not shown $(n=12)$. We also performed tissue transplantation assays coupled to DiI experiments at E12.5; the vMGE was dissected out and transplanted into a rostral or a caudal section to replace either the LGE or CGE, respectively. 
Then, the tissue transplanted from the vMGE and the one from the remaining dMGE/mMGE were labeled separately with DiI (Fig. 6E, I,M). The vMGE transplants show robust tangential migration to the cortex regardless of their new environment (Fig. 6M-P and data not shown) $(n=4)$ showing that E12.5 vMGE progenitor cells are specified to produce cells that tangentially migrate to the cortex. In addition, progenitors located in the remaining $\mathrm{dMGE} / \mathrm{mMGE}$ also retain their ability to migrate to the cortex (Fig. $6 F, G, J, K$ ). These experiments demonstrate that both the dMGE/mMGE and vMGE are sources of cells that tangentially migrate to the cortex.

URE2 and I12b/I56i mark overlapping and distinct subtypes of adult cortical interneurons

Expression of URE2 and I12b reporter transgenes persists postnatally in subsets of forebrain neurons. We focused on their expression in interneurons of the somatosensory and motor cortices of 5-week-old mice using double immunohistochemistry. We colabeled either URE2-lacZ+ or $I 12 b$-lac $Z+$ cells with GABA. We find that approximately two-thirds of GABA + cells $(\sim 66.1 \pm 2.8 \%)$ were $U R E 2-$ lacZ + , and nearly all of the URE2-lac $Z+$ cells express GABA ( $\sim 92.9 \pm 2.1 \%)$. In contrast, nearly all GABA + cells are I12b-lacZ+ ( 93.8 \pm $2.1 \%)$ and vice versa $(93.5 \pm 3.4 \%)$ (Fig. 7 and data not shown).

Next, we determined whether URE2lac $Z$ and I12b-lacZ were differentially expressed in subtypes of cortical interneurons. Thus, we colabeled URE2-lacZ+ and $I 12 b$-lac $Z+$ cells with the following subtype markers: calcium-binding proteins (CR, PV, and $\mathrm{CB}$ ) and neuropeptides (SOM, NPY, nNOS, and VIP). We find that URE2-lacZ is expressed in most PV $+(89 \pm 1 \%)$ (Figs. 7,8$), \mathrm{CR}+(88.4 \pm 0.8 \%)$ (Figs. 7, 9), NPY $+(92.8 \pm 3.2)$ (Fig. 7, supplemental Fig. S5, available at www.jneurosci.org as supplemental material), and nNOS $+(95.9 \pm 0.1 \%)$ (Fig. 7, supplemental Fig. S5, available at www.jneurosci.org as supplemental material) interneurons. Likewise, $I 12 b$-lacZ is also expressed in a large subset of these cells: PV $(85.5 \pm 3.3 \%)$ (Figs. 7, 8), CR (79.4 \pm 5.1\%) (Figs. 7, 9), NPY $(75.7 \pm 5.0 \%$ ) (Fig. 7, supplemental Fig. S5, available at www. jneurosci.org as supplemental material), and nNOS (27.3 \pm 7.1\%) (Fig. 7, supplemental Fig. S5, available at www. jneurosci.org as supplemental material).

However, URE2-lac $Z$ is expressed in only a very small number of SOM $+(10.2 \pm 1.2 \%)$ (Figs. 7, 8), VIP + (13.8 \pm 5.4\%) (Figs. $7,9)$, or $\mathrm{CB}+(14.7 \pm 1.1 \%)$ (Fig. 7$)$ interneurons. In contrast, $I 12 b-l a c Z$ is expressed in most of these three interneuron subtypes [SOM, $87.5 \pm 4.7 \%$ (Figs. 7, 8); VIP, $85.1 \pm 2.6 \%$ (Figs. 7, 9); CB, $85.5 \pm 5.7 \%$ (Fig. 7)].

We also double labeled I56i-lac $Z$ with the subtype markers mentioned above and found that this transgene is expressed in almost the same percentage of cells with regard to each subtype as I12b-lacZ (Figs. 7-9, supplemental Fig. S5, available at www. jneurosci.org as supplemental material). Thus, we conclude that URE2 and I12b/I56i mark common as well as distinct population(s) or subpopulation(s) of cortical interneurons in the adult mouse brain.

\section{Discussion}

Multiple enhancers regulate $D l x 1 / 2$ and $D l x 5 / 6$ expression in the LGE, MGE, and CGE

We provide evidence that the overall patterns of $D l x$ expression in the developing and mature brain represent the sum of patterns generated by distinct enhancer elements that may be regulated by distinct mechanisms. This conclusion is based on the detailed examination of cis-regulatory elements that control Dlx gene expression in the developing telencephalon. Three Dlx CREs active in the forebrain, URE2, I12b, and I56i, display partially overlapping activities in the basal ganglia anlage (Figs. 2, 3A-F; data not shown). The different activities of URE2, I12b, and I56i cannot be attributed to insertional effects of the transgene or differences in copy number. Patterns of transgene expression at selected time 


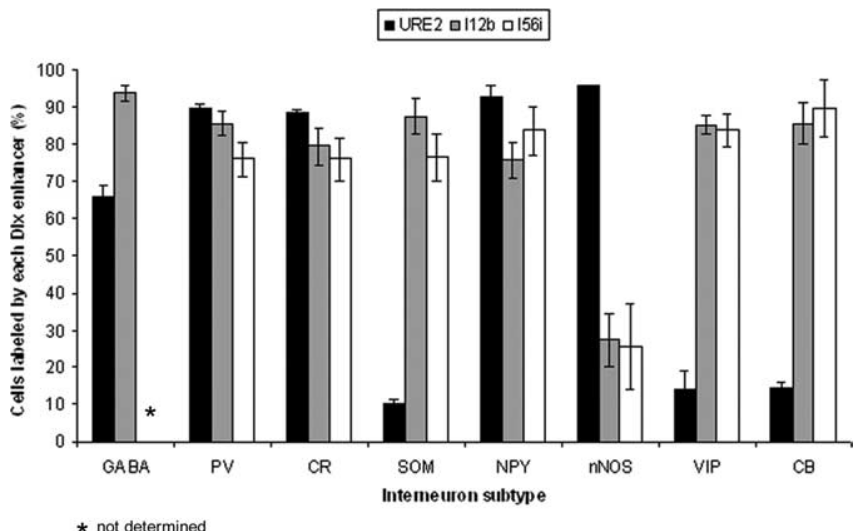

Figure 7. Percentage of cortical interneurons, classified according to marker gene expression, showing activity of the URE2, I12b, and I56i enhancers. Coexpression is an average from 8 to 10 sections of the somatosensory and motor cortices per mouse at P35 $(n=4)$. When both immunohistochemical signals were detected for both antigens in the same cell, regardless of signal intensity, the cell was counted as being positive for both antigens.
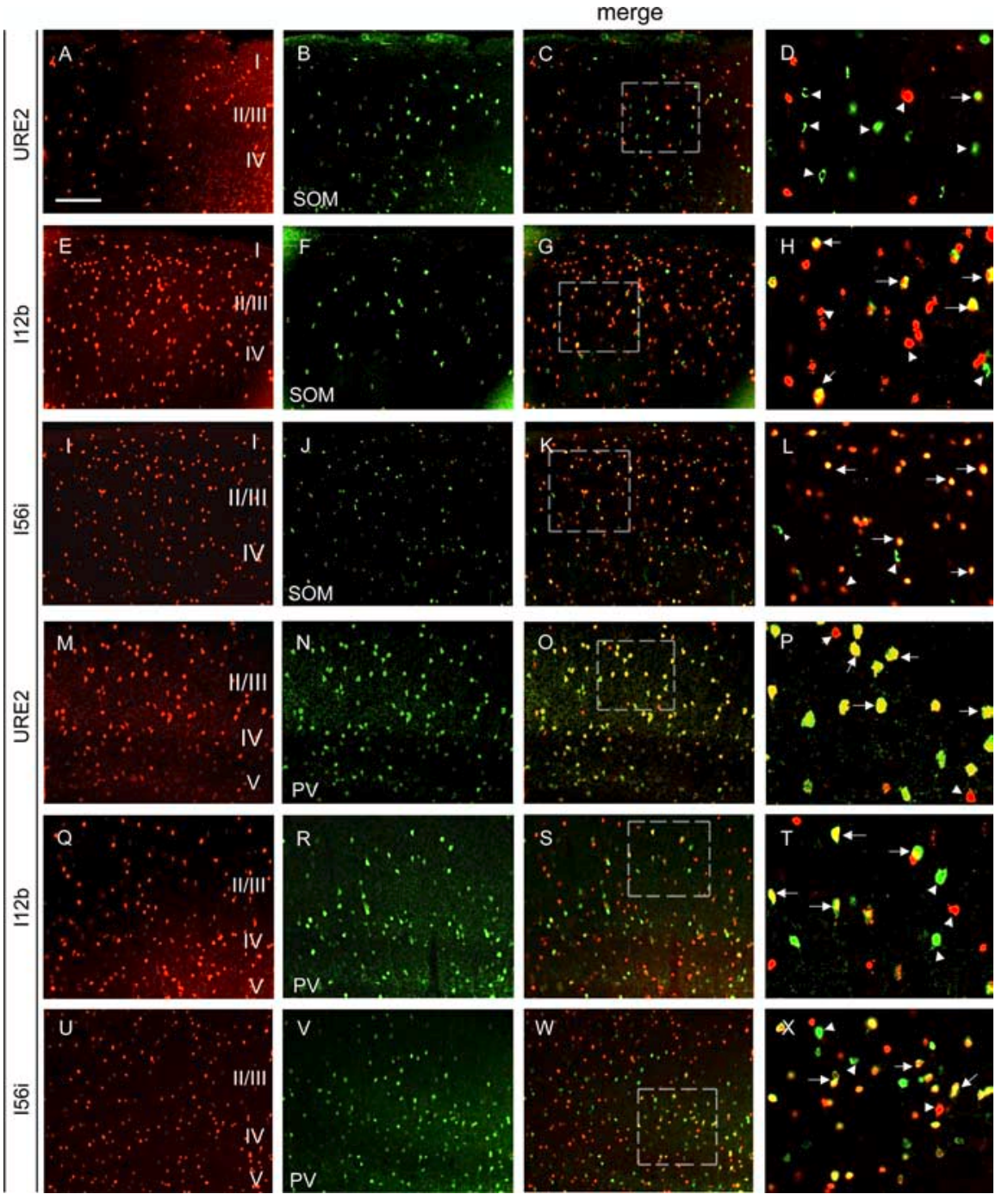

Figure 8. Coexpression of the SOM and PV interneuron markers with URE2-IaCZ, I12b-lacZ, and I56i-lacZ in the mouse adult somatosensory cortex at P35. Cells expressing URE2-lacZ $(\boldsymbol{A}-\boldsymbol{D}, \boldsymbol{M}-\boldsymbol{P}), I 12 b$-lacZ $(\boldsymbol{E}-\boldsymbol{H}, \mathbf{Q}-\boldsymbol{T})$, or I56i-lacZ $(\boldsymbol{I}-\boldsymbol{L}, \boldsymbol{U}-\boldsymbol{X})$ are shown in red. Interneurons expressing SOM $(\boldsymbol{A}-\boldsymbol{L})$ or $\mathrm{PV}(\boldsymbol{M}-\boldsymbol{X})$ are shown in green. $\boldsymbol{D}, \boldsymbol{H}, \boldsymbol{L}, \boldsymbol{P}, \boldsymbol{I}, \boldsymbol{X}$, Higher magnifications of boxes shown in $\boldsymbol{C}, \boldsymbol{G}, \boldsymbol{K}, \mathbf{O}, \mathbf{S}, \boldsymbol{W}$, respectively. $\mathbf{O}, \boldsymbol{P}$, Most PV + interneurons express URE2-lacZ. $\boldsymbol{C}, \boldsymbol{D}$, In contrast, only a few SOM + interneurons express URE2-lacZ. The /12b-lacZand /56i-lacZtransgenes are expressed in a large number of PV + as well as SOM + interneurons. Double- and single-labeled interneurons are indicated with arrows and arrowheads, respectively. Scale bar: (in $\boldsymbol{A}) \boldsymbol{A}-\boldsymbol{C}, \boldsymbol{E}-\boldsymbol{G}, \boldsymbol{I}-\boldsymbol{K}$, M-O, Q-S, U-W, $25 \mu \mathrm{m} ; \boldsymbol{D}, \boldsymbol{H}, \boldsymbol{L}, \boldsymbol{P}, \boldsymbol{T}, \boldsymbol{X}, 8.7 \mu \mathrm{m}$. points were reproducibly obtained from at least two independent was performed on at least two independent lines for each

The URE2, I12b, and I56i enhancers largely differ in sequence (Ghanem et al., 2003 and this study) and could thus contain , and $M$. Ekker, unpublished observations) support this themselves could be interacting with multiple en of auto-regulatory or cross-regulatory mechanisms (Zerucha et al., 2000; Zhou et al., 2004; Poitras et al., 2007) (Poitras, Ghanem,

Shipley, Hatch, and Ekker, unpublished observations).

The differential activities of URE2, I12b, and I56i in subdivisions of the LGE, MGE, and CGE suggest that the dorsal, medial, and ventral parts of these ganglionic eminences may generate distinct cell types. The Dlx progenitors born in these subpallial subdivisions have different molecular properties, which may influence the fate of these progenitors.

URE2 is the only CRE that is strongly active in a subset(s) of radially arranged cells in the VZ of the mLGE, mMGE, and mCGE between E11.5 and E12.5 (Figs. 2, 3, supplemental Fig. S1, available at www. jneurosci.org as supplemental material; data not shown) with patterns resembling the expression of $D l x 1$ and $D l \times 2$ in VZ cells (Porteus et al., 1994; Eisenstat et al., 1999). The strong expression of URE2-lacZ in the $\mathrm{VZ}$ is consistent with ongoing neurogenesis in that region between E11.5 and E14.5 (Anthony et al., 2004). These URE2positive cells could be radial glia and/or neuronal progenitors considering that a large subset of radial glia in the ganglionic eminence $(>55 \%)$ produce neurons between E11.5 and E14.5 (Anthony et al., 2004). By E14.5, most progenitors derived from radial glia enter gliogenesis (Anthony et al., 2004), a time when URE2 activity in the VZ gradually diminishes until E15.5, when $\beta$-galactosidase is detected very weakly.

Distinct groups of cells show differential activities of URE2 and I12b in the SVZ and MZ of the LGE, MGE, and CGE at E11.5-E13.5 (Figs. 2-4). I56i and I12b are both active in the LGE, MGE, and CGE in most SVZ cells and a substantial number of MZ cells (Figs. 2, 3D-F, supplemental Fig. S1 $D-F$, available at www.jneurosci.org as supplemental material). Thus, these two CREs are likely to be active in common cell populations at E11.5-E13.5 as well as at later times.

The overlapping activities of the CREs recapitulate similarities in the endogenous Dlx gene expression. Previous work provided evidence that similarities in Dlx ex- 
pression patterns (Liu et al., 1997; Eisenstat et al., 1999) could be explained by cross-regulatory interactions between $D l x$ genes. Thus $D l x 1$ and/or $D l x 2$ are thought to be upstream regulators of $D l \times 5$ and Dlx6, because $D l x 1 / D l x 2$ null mice show loss of $D l \times 5 / D l x 6$ expression in most of the telencephalon, except in cells derived from the septal region (Anderson et al., 1997b; Zerucha et al., 2000). The I56i enhancer from the $D l \times 5 / D l x 6$ locus is regulated by DLX1 and/or DLX2 both in vitro and in vivo (Zerucha et al., 2000; Stuhmer et al., 2002a; Zhou et al., 2004).

\section{Distinct cell populations tangentially migrate to the cortex between E11.5 and E13.5}

Differential spatiotemporal activities of URE2, I12b, and I56i are detected in tangentially migrating cells that are derived from the MGE and CGE between E11.5 and E13.5. URE2-lacZ expression in tangentially migrating cells is detected at least $1 \mathrm{~d}$ later than for the $I 12 b$-lacZ or I56i-lacZ transgenes. We propose that the URE2lacZ-expressing cells migrating to the cortex are primarily derived from the mMGE and mCGE based on the activity of the enhancer in these progenitor domains at E12.5. Because we do not detect expression of the URE2-lacZ transgene in migrating cells at this stage, this suggests that migrating cells at E12.5 originate mainly from regions of low URE2 activity, namely the dMGE, vMGE, dCGE, and vCGE. At later stages, we suggest that the mMGE contributes tangentially migrating cells, coincident with the increase in URE2-lacZ expression. Alternatively, the increase in migrating cells expressing URE2-lacZ at later stages could be attributable to increased URE2 enhancer activity in preexisting cells that did not express the transgene previously.

At E13.5, the majority of cells expressing URE2-lacZ but not I12b-lacZ (URE2-lacZ+/I12b-lacZ-) follow the IZ as their major route of migration.

Together, our data suggest that cells expressing various combinations of URE2-lacZ+,I12b-lacZ+ and I56i-lacZ+ may correspond to distinct populations of migrating cells, and this may be associated with the distinct fates of these cells once they have reached their destination in the cortex.

Using tissue transplantation coupled to DiI labeling in slice cultures, we provide evidence that the $\mathrm{dMGE} / \mathrm{mMGE}$ and vMGE are both sources of tangentially migrating cells between E12.5 and E13.5. Alternatively, some of the dMGE/mMGE migrating cells could derive from vMGE and are thus labeled at different positions along their migratory routes.

\section{Dlx CREs are active in distinct subtypes of cortical} interneurons in adult mice

$D l x$ genes are expressed in most mouse neocortical GABAergic interneurons (Stuhmer et al., 2002b; Cobos et al., 2005, 2006). merge
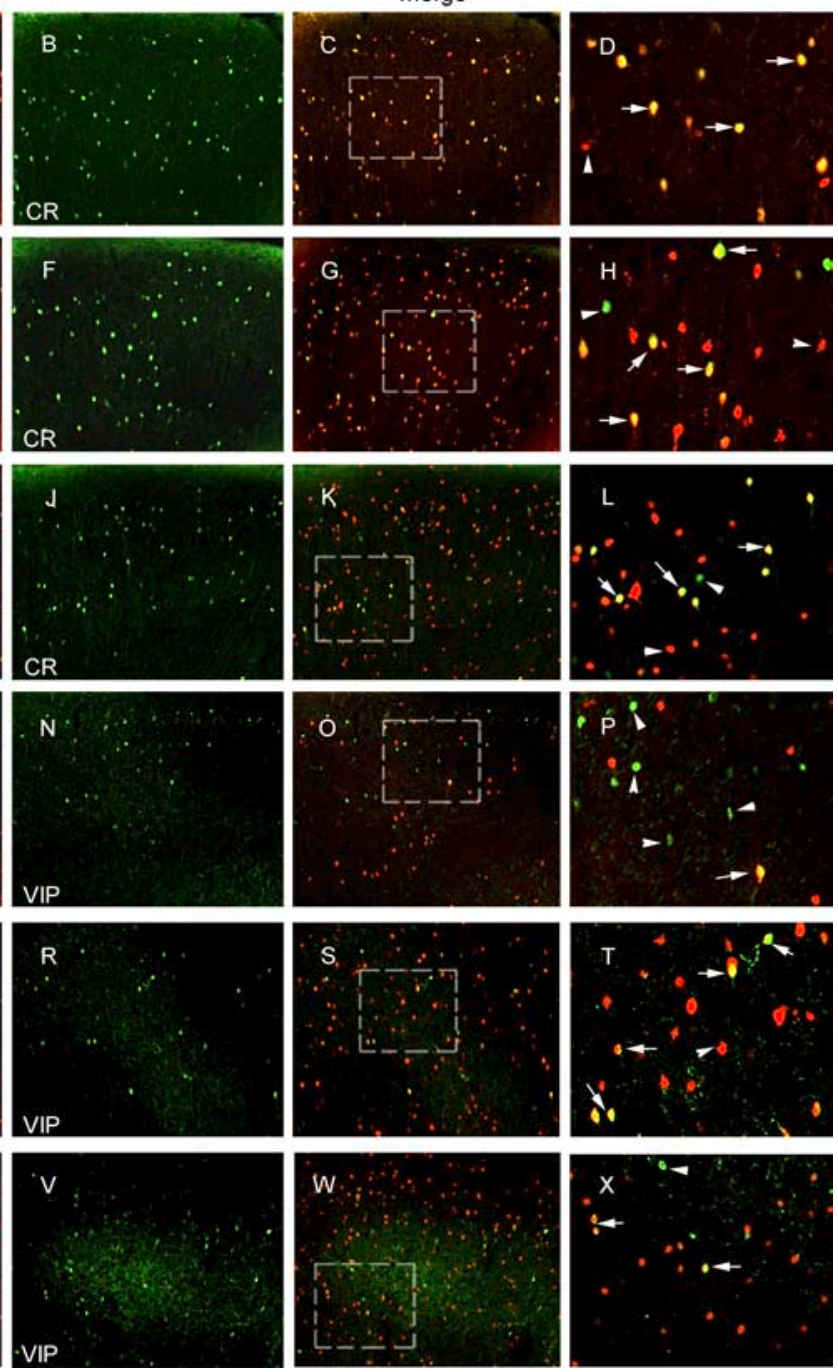

VIP

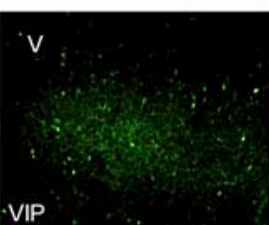

Figure 9. Coexpression of the (R and VIP interneuron markers with URE2-lacZ, I12b-lacZ, and I56i-lacZ in the mouse adult somatosensory cortex at P35. Cells expressing URE2-IacZ (A-D, $\boldsymbol{M}-\boldsymbol{P}), I 12 b$-lacZ $(\boldsymbol{E}-\boldsymbol{H}, \mathbf{Q}-\boldsymbol{T})$, or I56i-lacZ $(\boldsymbol{I}-\boldsymbol{L}, \boldsymbol{U}-\boldsymbol{X})$ are shown 政 URE2-lacZ. The /12b-lacZ and I56i-lacZ transgenes are expressed in a large number of CR + as well as VIP + interneurons. Doubleand single-labeled interneurons are indicated with arrows and arrowheads, respectively. Scale bar: (in $\boldsymbol{A}) \boldsymbol{A}-\boldsymbol{C}, \boldsymbol{E}-\mathbf{G}, \boldsymbol{I}-\boldsymbol{K}, \boldsymbol{M}-\mathbf{0}$, Q-S, U-W, $25 \mu \mathrm{m} ; \boldsymbol{D}, \boldsymbol{H}, \boldsymbol{L}, \boldsymbol{P}, \boldsymbol{T}, \boldsymbol{X}, 8.7 \mu \mathrm{m}$.

URE2 and I12b are likely to be involved in the regulation of $D l x 1$ and Dlx 2 in adult cortical GABAeric neurons, as they are active in $66 \%$ and $93 \%$ of these cells, respectively (Fig. 7 and data not shown). Most URE2-lacZ+ ( 92\%) and I12b-lacZ+ ( 93\%) cells in the cortex contain GABA (data not shown).

PV-, SOM-, and CR-positive interneurons constitute distinct subtypes of cortical GABAergic neurons (Markram et al., 2004). $I 12 b$-lacZ and I56i-lacZ, but not URE2-lacZ, are expressed in the majority of interneurons expressing SOM, VIP, and CB (Figs. 7-9). In contrast, URE2-lacZ is expressed in most PV-, CR-, NPY-, and nNOS-expressing interneurons ( $>88 \%$ of each subtype) (Figs. 7-9, supplemental Fig. S5, available at www.jneurosci.org as supplemental material). I12b-lacZ and I56i-lacZ are expressed in many but not all interneurons belonging to these subtypes ( $>75-$ $87 \%$ except for nNOS 27\%) (Figs. 7-9, supplemental Fig. S5, available at www.jneurosci.org as supplemental material).

Previous studies showed that PV- and SOM-expressing interneurons derive primarily from progenitors located in the MGE 
A
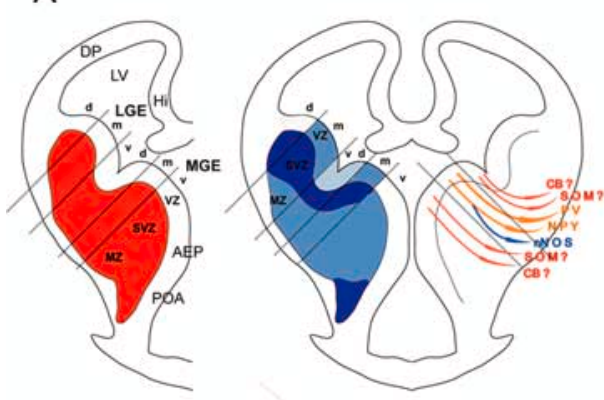

B
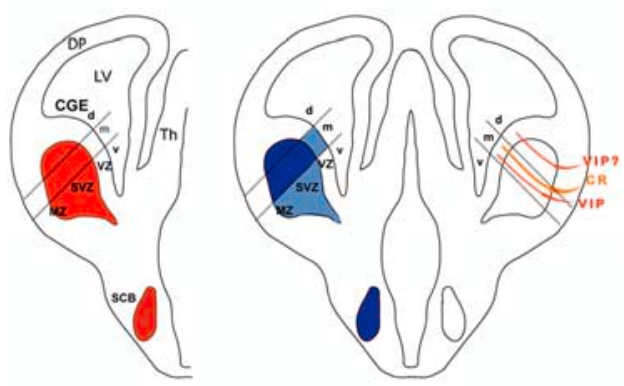

URE2-positive domains in the VZ at E12.5 and their hypothesized cortical interneurons derivatives

\begin{tabular}{|c|c|c|c|}
\hline Subdivisions & $\begin{array}{l}\text { URE2 } \\
\text { activity }\end{array}$ & \multicolumn{2}{|c|}{$\begin{array}{l}\text { Interneuron } \\
\text { subtype(s) }\end{array}$} \\
\hline dLGE & $\cdot$ & $O B^{*}:$ & $?$ \\
\hline mLGE & +++ & & \\
\hline VLGE & + & & \\
\hline dMGE & + & $\begin{array}{l}\text { SOM: } \\
\text { CB: }\end{array}$ & $?$ \\
\hline \multirow[t]{5}{*}{ mMGE } & \multirow{5}{*}{++} & SOM: & + \\
\hline & & CB: & + \\
\hline & & PV: & +++ \\
\hline & & nNOS & +++ \\
\hline & & nNPY: & +++ \\
\hline VMGE & - & $\begin{array}{l}\text { SOM: } \\
\text { CB: }\end{array}$ & $?$ \\
\hline dCGE & - & VIP: & $?$ \\
\hline \multirow[t]{2}{*}{ mCGE } & \multirow[t]{2}{*}{++} & VIP: & + \\
\hline & & CR: & +++ \\
\hline VCGE & $\cdot$ & & \\
\hline
\end{tabular}

- Not detected

+ Weak activity / few interneuron

+. Intermediate activity / many interneuro

+*+ Strong activity $/$ most interneurons

$12 \mathrm{~b}$ activity

Strong URE2 activity

Weak URE2 activity

Very weak URE2 activity

Figure 10. Proposed model for the origin of adult cortical interneurons subtypes in the embryonic mouse brain. $A, B, S$ Chematic representation of 12.5 coronal hemisections/sections at the level of the MGE $(\boldsymbol{A})$ and the $C G E(\boldsymbol{B})$. Enhancer activities of $\mathrm{I} 12 \mathrm{~b}$ (red) and URE2 (blue) in the MGE and (GE are depicted in the left hemispheres in $\boldsymbol{A}$ and $\boldsymbol{B}$. Colored arrows in the right hemispheres in $\boldsymbol{A}$ and $\boldsymbol{B}$ indicate the proposed origin(s) of D/x-progenitor cells that will give rise to various subtypes of cortical GABAergic interneurons. D/x-progenitors that express URE2-lacZ and $/ 12 b$-lacZ are represented by blue and red arrows, respectively. Progenitors that express both transgenes are shown in orange. D/x-PV-progenitors are possibly derived from the mMGE whereas D/xSOM-progenitors could derive from the dMGE and/or the vMGE (see Discussion). DIx-NPY-progenitors and D/x-nNOS-progenitors are probably derived from the mMGE; some of these cells could also form subpopulations of DIx-SOM-progenitors. In the CGE, DIX-VIP-progenitors and DIX-CR-progenitors are probably derived from the mCGE but could also derive from the dCGE (see Discussion). Symbols are the same as in Figure 2. Hi, Hippocampus; Th, thalamus; d, dorsal; m, medial; v, ventral.

between E12.5 and E16.5 (Xu et al., 2004; Butt et al., 2005). Our data support these results but raise the interesting possibility that distinct $D l x$ progenitors originating from MGE subdivisions (i.e., dMGE, mMGE, and/or vMGE) contribute to the various interneuron subtypes. Because most PV-neurons express URE2-lacZ, it is possible that this subtype is derived from progenitors in which the URE2 CRE is active and which are born in the mMGE rather than in the vMGE (Fig. 10A,C). Furthermore, they probably correspond to the URE2-lacZ+ cells that undergo robust tangential migrations to the cortex between E13.5 and E14.5. In contrast, SOM interneurons that exclusively express I12b-lacZ may derive from progenitors born primarily in the dMGE and/or vMGE (Fig. 10A,C).

URE2-lacZ is only found in $\sim 10 \%$ of the SOM + cells, but in $\sim 92 \%$ of the NPY + cells, suggesting that these two subtype(s) may not be largely overlapping in the mouse somatosensory cortex as it is the case in the rat frontal and visual cortices (Kubota et al., 1994; Freund and Buzsaki, 1996; Gonchar and Burkhalter, 1997). These differences may be species- and/or region-related or may stem from the fact that we pooled cell counts from all six layers, which could have masked some of the differences that are layer- and/or subtype-specific. Thus, our results suggest that at least some NPY-positive neurons could derive from distinct pro- genitors compared with the SOMexpressing neurons; however, the place of origin of these progenitors in the MGE remains to be determined (Fig. $10 \mathrm{~A}, \mathrm{C}$ ).

CR-positive cortical interneurons express URE2-lacZ $(\sim 88 \%)$ and I12b-lacZ $(\sim 80 \%)$, suggesting that they may derive from URE2-lacZ +/I12b-lacZ + cells found in the mCGE between E13.5 and E14.5 (Fig. 10B). Arguments that support this conclusion and favor the mCGE over the dCGE and vCGE include the following: (1) URE2 is only active in the VZ of the mCGE (Fig. 2J, supplemental Fig. S1 $A-C$, available at www.jneurosci.org as supplemental material). (2) Previous studies have shown that interneurons expressing CR are derived exclusively from progenitors found in the dorsal CGE between E13.5 and E15.5 (Xu et al., 2004; Butt et al., 2005); however, we do not know whether this domain includes both the dCGE and mCGE.

In utero transplantation studies performed by Butt et al. (2005) showed that most VIP progenitors are located in the dorsal part of CGE; again, we do not know whether this domain includes both the dCGE and mCGE. VIP + interneurons mainly express I12b-lacZ ( 85\%). The URE2-lacZ transgene is expressed in only $\sim 14 \%$ of VIP-expressing cells but in $88 \%$ of $\mathrm{CR}+$ neurons. In the rat frontal cortex, the CR and VIP populations are largely overlapping in deep cortical layers and partially overlapping in superficial layers (Kubota et al., 1994), suggesting a common origin for these neurons. This contrasts with the differential activities of URE2 and I12b observed in CR + and VIP+ interneurons. Although expression of the reporter transgenes was observed at multiple prenatal and postnatal time points, we cannot formally exclude that, at intermediate time points, especially after birth, the CRE expression either began and/or terminated in certain cell populations. Therefore, the results presented in this study do not constitute direct evidence for the existence of a direct lineage relationship between tangentially migrating cells expressing one or more reporter transgenes and the generation of specific subtype(s) of adult cortical interneurons.

In summary, these studies demonstrate that distinct $D l x$ enhancer elements define molecularly distinct subdivisions of the LGE, MGE, and CGE and distinguish some adult cortical interneuron subtypes. Genetic analyses in mice that alter enhancer function, or use these enhancers to perform formal lineage analyses, will establish the function of the individual $D l x$ enhancer elements.

\section{References}

Anderson SA, Eisenstat DD, Shi L, Rubenstein JL (1997a) Interneuron migration from basal forebrain to neocortex: dependence on Dlx genes. Science 278:474-476.

Anderson SA, Qiu M, Bulfone A, Eisenstat DD, Meneses J, Pedersen R, Rubenstein JL (1997b) Mutations of the homeobox genes Dlx-1 and 
Dlx-2 disrupt the striatal subventricular zone and differentiation of late born striatal neurons. Neuron 19:27-37.

Anderson SA, Marin O, Horn C, Jennings K, Rubenstein JL (2001) Distinct cortical migrations from the medial and lateral ganglionic eminences. Development 128:353-363.

Anderson SA, Kaznowski CE, Horn C, Rubenstein JL, McConnell SK (2002) Distinct origins of neocortical projection neurons and interneurons in vivo. Cereb Cortex 12:702-709.

Anthony TE, Klein C, Fishell G, Heintz N (2004) Radial glia serve as neuronal progenitors in all regions of the central nervous system. Neuron 41:881-890.

Butt SJ, Fuccillo M, Nery S, Noctor S, Kriegstein A, Corbin JG, Fishell G (2005) The temporal and spatial origins of cortical interneurons predict their physiological subtype. Neuron 48:591-604.

Cobos I, Calcagnotto ME, Vilaythong AJ, Thwin MT, Noebels JL, Baraban SC, Rubenstein JL (2005) Mice lacking Dlxl show subtype-specific loss of interneurons, reduced inhibition and epilepsy. Nat Neurosci 8:1059-1068.

Cobos I, Long JE, Thwin MT (2006) Cellular patterns of transcription factor expression in developing cortical interneurons. Cereb Cortex [Suppl] 1:i82-i88.

Corbin JG, Nery S, Fishell G (2001) Telencephalic cells take a tangent: nonradial migration in the mammalian forebrain. Nat Neurosci 4:1177-1182.

DeFelipe J, Farinas I (1992) The pyramidal neuron of the cerebral cortex: morphological and chemical characteristics of the synaptic inputs. Prog Neurobiol 39:563-607.

Eisenstat DD, Liu JK, Mione M, Zhong W, Yu G, Anderson SA, Ghattas I, Puelles L, Rubenstein JL (1999) DLX-1, DLX-2, and DLX-5 expression define distinct stages of basal forebrain differentiation. J Comp Neurol 414:217-237.

Ferguson KL, McClellan KA, Vanderluit JL, McIntosh WC, Schuurmans C, Polleux F, Slack RS (2005) A cell-autonomous requirement for the cell cycle regulatory protein, $\mathrm{Rb}$, in neuronal migration. EMBO J 24:43814391.

Freund TF, Buzsaki G (1996) Interneurons of the hippocampus. Hippocampus 6:347-470.

Ghanem N, Jarinova O, Amores A, Hatch G, Park BK, Rubenstein JL, Ekker M (2003) Regulatory roles of conserved intergenic domains in vertebrate Dlx bigene clusters. Genome Res 13:533-543.

Gonchar Y, Burkhalter A (1997) Three distinct families of GABAergic neurons in rat visual cortex. Cereb Cortex 7:347-358.

Hendry SH, Schwark HD, Jones EG, Yan J (1987) Numbers and proportions of GABA-immunoreactive neurons in different areas of monkey cerebral cortex. J Neurosci 7:1503-1519.

Kubota Y, Hattori R, Yui Y (1994) Three distinct subpopulations of GABAergic neurons in rat frontal agranular cortex. Brain Res 649:159-173.

Lavdas AA, Grigoriou M, Pachnis V, Parnavelas JG (1999) The medial ganglionic eminence gives rise to a population of early neurons in the developing cerebral cortex. J Neurosci 19:7881-7888.

Liu JK, Ghattas I, Liu S, Chen S, Rubenstein JL (1997) Dlx genes encode DNA-binding proteins that are expressed in an overlapping and sequential pattern during basal ganglia differentiation. Dev Dyn 210:498-512.

Marin O, Rubenstein JL (2001) A long, remarkable journey: tangential migration in the telencephalon. Nat Rev Neurosci 2:780-790.
Marin O, Rubenstein JL (2003) Cell migration in the forebrain. Annu Rev Neurosci 26:441-483.

Markram H, Toledo-Rodriguez M, Wang Y, Gupta A, Silberberg G, Wu C (2004) Interneurons of the neocortical inhibitory system. Nat Rev Neurosci 5:793-807.

Meinecke DL, Peters A (1987) GABA immunoreactive neurons in rat visual cortex. J Comp Neurol 261:388-404.

Nery S, Fishell G, Corbin JG (2002) The caudal ganglionic eminence is a source of distinct cortical and subcortical cell populations. Nat Neurosci 5:1279-1287.

Panganiban G, Rubenstein JL (2002) Developmental functions of the Distal-less/Dlx homeobox genes. Development 129:4371-4386.

Parnavelas JG (2000) The origin and migration of cortical neurones: new vistas. Trends Neurosci 23:126-131.

Parnavelas JG, Lieberman AR, Webster KE (1977) Organization of neurons in the visual cortex, area 17, of the rat. J Anat 124:305-322.

Peters A, Saint Marie RL (1984) Smooth and sparsely spinous nonpyramidal cells forming local axonal plexuses. In: Cerebral cortex, Vol 1 (Peters A, Jones EG, eds), pp 419-445. New York: Plenum.

Poitras L, Ghanem N, Hatch G, Ekker M (2007) The pro-neural determinant Mash 1 regulates $D l x 1 / 2$ forebrain gene expression through the $112 \mathrm{~b}$ intergenic enhancer. Development 134:1755-1765.

Porteus MH, Bulfone A, Liu JK, Puelles L, Lo LC, Rubenstein JL (1994) DLX-2, MASH-1, and MAP-2 expression and bromodeoxyuridine incorporation define molecularly distinct cell populations in the embryonic mouse forebrain. J Neurosci 14:6370-6383.

Stuhmer T, Anderson SA, Ekker M, Rubenstein JL (2002a) Ectopic expression of the Dlx genes induces glutamic acid decarboxylase and Dlx expression. Development 129:245-252.

Stuhmer T, Puelles L, Ekker M, Rubenstein JL (2002b) Expression from a $D l x$ gene enhancer marks adult mouse cortical GABAergic neurons. Cereb Cortex 12:75-85.

Valcanis H, Tan SS (2003) Layer specification of transplanted interneurons in developing mouse neocortex. J Neurosci 23:5113-5122.

Wichterle H, Turnbull DH, Nery S, Fishell G, Alvarez-Buylla A (2001) In utero fate mapping reveals distinct migratory pathways and fates of neurons born in the mammalian basal forebrain. Development 128:3759-3771.

Wonders CP, Anderson SA (2006) The origin and specification of cortical interneurons. Nat Rev Neurosci 7:687-696.

Xu Q, Cobos I, De La Cruz E, Rubenstein JL, Anderson SA (2004) Origins of cortical interneuron subtypes. J Neurosci 24:2612-2622.

Yee SP, Rigby PW (1993) The regulation of myogenin gene expression during the embryonic development of the mouse. Genes Dev 7:1277-1289.

Zerucha T, Stuhmer T, Hatch G, Park BK, Long Q, Yu G, Gambarotta A, Schultz JR, Rubenstein JL, Ekker M (2000) A highly conserved enhancer in the $D l \times 5 / D l x 6$ intergenic region is the site of cross-regulatory interactions between $D l x$ genes in the embryonic forebrain. J Neurosci 20:709-721.

Zhou QP, Le TN, Qiu X, Spencer V, de Melo J, Du G, Plews M, Fonseca M, Sun JM, Davie JR, Eisenstat DD (2004) Identification of a direct Dlx homeodomain target in the developing mouse forebrain and retina by optimization of chromatin immunoprecipitation. Nucleic Acids Res 32: 884-892. 